\title{
Student's Section
}

\section{Parental transmission of type 2 diabetes mellitus among patients attending a tertiary care hospital}

\section{Manasi Gupta ${ }^{a, *}$, Asif Iqbal ${ }^{b}$, Suma Nair ${ }^{c}$, Muralidhar Varma ${ }^{d}$, Sudha Vidyasagar ${ }^{e}$}

${ }^{a}$ Medical Student, Kasturba Medical College and Hospital, Manipal University, Manipal 576104, Karnataka, India

${ }^{\mathrm{b}}$ Hospitalist, Internal Medicine, Mediclinic Hospital, DHCC, Dubai

c Associate Professor, Department of Community Medicine, Kasturba Medical College and Hospital, Manipal University, Manipal 576104, Karnataka, India

d Associate Professor, Department of General Medicine, Kasturba Medical College and Hospital, Manipal University, Manipal 576104, Karnataka, India

e Professor, Department of General Medicine, Kasturba Medical College and Hospital, Manipal University, Manipal 576104, Karnataka, India

\section{A R T I C L E I N F O}

Article history:

Received 3 September 2014

Accepted 20 April 2015

Available online 13 May 2015

Keywords:

Type 2 diabetes mellitus

Inheritance

Father

Mother

\begin{abstract}
A B S T R A C T
Problem considered: Type 2 Diabetes Mellitus is a heritable condition. Some studies suggest a strong maternal association while others claim paternal transmission of diabetes to be more significant. The present study was aimed at identifying the role of parental transmission in Type 2 diabetic patients with family history of diabetes.

Methods: This was a cross-sectional study carried out among individuals diagnosed with Type 2 Diabetes Mellitus (DM) and having a family history of the same attending the General Medicine OPD in a tertiary care hospital. Consenting consecutive patients fulfilling the inclusion criteria were enrolled into the study. Demographic characteristics, age at onset of Type 2 Diabetes and parental history of the disease were obtained in detail.

Results: Of the 174 participants enrolled into the study nearly $66 \%$ were males. Maternal history of DM (65\%) was more commonly observed as compared to paternal history (57\%) and nearly $23 \%$ had a history of both parents being diabetic. Fifty two percent gave a sibling history of type $2 \mathrm{DM}$. Siblings of patients with affected mothers had a greater likelihood of diabetes $(77.8 \%)$ than those with affected fathers $(51 \%)(P=0.001)$. More males had a brother who was diabetic (66\%), likewise more females had a sister who was diabetic (55\%). Conclusion: Maternal inheritance of DM appears to be more common and there is a significant association of type 2 diabetes among siblings of patients with affected mothers. This apparent association is an area that needs to be explored further.

Copyright $\odot$ 2015, INDIACLEN. Publishing Services by Reed Elsevier India Pvt Ltd. All rights
\end{abstract} reserved.

\footnotetext{
* Corresponding author. Tel.: +919535679691.

E-mail address: manasigupta31@yahoo.in (M. Gupta).
} http://dx.doi.org/10.1016/j.cegh.2015.04.002

2213-3984/Copyright @ 2015, INDIACLEN. Publishing Services by Reed Elsevier India Pvt Ltd. All rights reserved. 


\section{Introduction}

The incidence of Type 2 Diabetes Mellitus (DM) is increasing rapidly and India has the second largest diabetic population in the world next to only China. ${ }^{1}$ The risk of developing the disease increases with age, obesity, and lack of physical activity and is also associated with a strong genetic predisposition. ${ }^{2}$ Family studies have shown that type $2 \mathrm{DM}$ is a heritable condition. ${ }^{3-5}$ However, there appears inconsistency in these findings with some studies suggesting a strong maternal association while others claim paternal transmission of diabetes to be more significant. ${ }^{3-5}$

Maternal transmission appears to be an important factor that is increasingly being studied and various mechanisms have been proposed for this transmissibility such as maternally inherited mitochondrial DNA mutations and deletions, intrauterine environment and behavioral risk factors particularly non genetic variation in obesity passed on preferentially by the mother. ${ }^{6-8}$ More recent studies however, suggest that though these mechanisms may be important in the transmission of diabetes they probably cannot explain the excess in maternal transmission. $^{9}$ The present study was therefore carried out with the aim of identifying the profile and familial inheritance in type 2 diabetic patients with family history of diabetes.

\section{Methods}

This was a cross-sectional study carried out over a period of 3 months amongst outpatients and inpatients of the department of general medicine as well as those attending the diabetic clinic of a tertiary care hospital in southern India. The study population included all patients attending these facilities during this period with a diagnosis of type $2 \mathrm{DM}$ and giving a family history of type $2 \mathrm{DM}$. Patients with type $1 \mathrm{DM}$, Gestational DM and other forms of diabetes like steroid induced diabetes and Latent Autoimmune Diabetes in Adults (LADA) were not included in the study.

Considering a $13 \%$ population proportion of maternal diabetes from previous studies ${ }^{9}$ for an absolute precision of $5 \%$ at $95 \%$ level of confidence, the required minimum sample size was 174 . The required sample of consecutive out patients and in patients fulfilling the inclusion criteria were recruited into the study. Institutional ethical clearance was obtained prior to carrying out the study. An informed consent was obtained from all patients and details of the patients were kept confidential giving them a coded identity.

Study variables included socio-demographic characteristics like age, sex, occupation and place of residence; anthropometric measurements corresponding to weight, height and Body Mass Index (BMI) and biochemical parameters as $\mathrm{HbA}_{1} \mathrm{C}$ values. Age at onset of type $2 \mathrm{DM}$ and a detailed family history of type $2 \mathrm{DM}$ were also queried. Weight was recorded using a standard weighing scale, kept on a firm horizontal surface to the nearest $100 \mathrm{gm}$. Height was recorded using a mobile stadiometer to the nearest $1 \mathrm{~cm}$. Body mass index (BMI) was calculated using the formula, weight $(\mathrm{kg}) / \mathrm{height}\left(\mathrm{m}^{2}\right)$ and categorized as per the WHO international criteria ${ }^{10}$ and $\mathrm{HbA}_{1} \mathrm{C}$ values were calculated using HPLC-D10 method. Age at which the patient was diagnosed to have type $2 \mathrm{DM}$ was taken as the age of onset of the disease. Information pertaining to age of onset and duration of type $2 \mathrm{DM}$ in parents and siblings of the participants were also collected. Parents were confirmed to have Type $2 \mathrm{DM}$ on the basis of history and age of onset. ${ }^{11}$

Statistical analysis was carried out using SPSS version 15 . Pedigree charts were used to group and analyze the maternal and paternal inheritance of diabetes.

\section{Results}

The baseline characteristics of the study participants are as illustrated in Table 1. Of the 174 participants enrolled into the study majority (82\%) were over the age of 40 and employed (72\%). Most of the females were housewives (78\%) and a substantial number of them (64.4\%) were overweight with a $\mathrm{BMI}>25$. Marginally more number gave a history of maternal diabetes $(65.5 \%)$ as compared to paternal history of diabetes $(57.5 \%)$, while $39(23 \%)$ of the study participants had history of diabetes in both parents. Nearly $52 \%$ had a sibling history of type 2 DM.

More males were noted to have a brother who was diabetic (66\%), likewise more females had a sister who was diabetic (55\%). This association was however not significant. Patients with affected mothers had a greater likelihood of diabetes (77.8\%) in siblings than those with affected fathers (51\%) as shown in Table 2 and this association was statistically significant. Interestingly, paternal history of type $2 \mathrm{DM}$ showed a significant association with early onset of the disease, which was defined as less than 40 years. Onset of paternal type $2 \mathrm{DM}$ at less than 50 years of age was also noted to have a statistically significant association with early onset of the disease. We however, did not find a similar association with maternal factors (Table 3).

\section{Discussion}

The study shows a male preponderance of type $2 \mathrm{DM}$ as shown by other studies. ${ }^{3,12}$ This could be a health care seeking bias

Table 1 - Baseline characteristics of study participants $\mathbf{N}=174$.

\begin{tabular}{lcc} 
Variable & Frequency & Percentage (\%) \\
\hline Gender: & & \\
Male & 115 & 66.1 \\
Female & 59 & 33.9 \\
Age group: & & \\
$\quad<=30$ & 07 & 04.0 \\
$31-50$ & 83 & 47.8 \\
$51-70$ & 78 & 44.8 \\
$>=71$ & 06 & 03.4 \\
BMI: & & \\
Underweight & 09 & 05.2 \\
Normal & 85 & 48.8 \\
Overweight & 52 & 29.9 \\
Obese & 28 & 16.1 \\
\hline
\end{tabular}


Table 2 - Association between family history \& type 2 DM in siblings.

\begin{tabular}{lcccc} 
& \multicolumn{2}{c}{ Type 2 DM in siblings } & OR (95\% CI) & P value \\
\cline { 2 - 4 } Factor & Present & Absent & & \\
\hline Maternal history of DM & $70(77.8 \%)$ & $44(52.4 \%)$ & $3.18(1.65,6.13)$ & 0.001 \\
Paternal history of DM & $46(51.1 \%)$ & $54(64.3 \%)$ & $0.58(0.31,1.06)$ & \\
\hline
\end{tabular}

\section{Table 3 - Association between family history \& early onset of DM.}

\begin{tabular}{lccc} 
Factor & \multicolumn{2}{c}{ Early onset of type 2 DM } & Or (95\% CI) \\
\cline { 2 - 3 } & $\leq 40$ years & $>40$ years & \\
\hline $\begin{array}{l}\text { Paternal history } \\
\text { of DM }\end{array}$ & $52(69.3 \%)$ & $48(48.5 \%)$ & $2.402(1.28,4.50)$ \\
$\begin{array}{c}\text { Maternal history } \\
\text { of DM }\end{array}$ & $48(64.0 \%)$ & $65(65.7 \%)$ & $0.930(0.49,1.74)$ \\
$\begin{array}{l}\text { Onset of maternal } \\
\text { DM at }<50 \text { years }\end{array}$ & $16(35.6 \%)$ & $13(26.0 \%)$ & $0.637(0.26,1.53)$ \\
$\begin{array}{l}\text { Onset of paternal } \\
\text { DM at }<50 \text { years }\end{array}$ & $22(48.9 \%)$ & $06(20.0 \%)$ & $3.826(1.31,11.13)$ \\
\hline
\end{tabular}

inherent to developing countries, where more men seek tertiary care treatment as compared to women. Gale EA and Gillespie $\mathrm{KM}$ reported equal prevalence among men and women in most populations, with some evidence of male preponderance in early middle age. ${ }^{13}$ Most of the study participants were middle aged men and women which is in concordance with other studies. ${ }^{12,14}$ Women were more likely to have a higher BMI and this association was statistically significant $(P=0.001)$. Logue $J$ et al in a population based study found that men are at greater risk of developing type 2 diabetes at a lower BMI than women. ${ }^{15}$

Maternal history of diabetes was more than paternal history $(65.5 \%$ vs $57.5 \%)$ but was not significant as shown in a study conducted by $\mathrm{Mc}$ Carthy $\mathrm{M}$ et al, on a south Indian population in London. ${ }^{16}$ Thorand $\mathrm{B}$ et al, also did not support excess maternal transmission. ${ }^{9}$ But maternal history of type 2 $\mathrm{DM}$ is seen to be a risk factor for type $2 \mathrm{DM}$ in the siblings of our study participants $(P=0.001)$. This was also noted by Karter AJ et al, where in siblings of probands with affected mothers had a greater prevalence of diabetes $(20 \%)$ than those with affected fathers.

Having a paternal history of type $2 \mathrm{DM}$ was noted to be more of a risk for a female patient as compared to a maternal history. Likewise men had a higher risk with a maternal history of DM. The occurrence of type $2 \mathrm{DM}$ among same gender siblings was more common. However these associations were statistically not significant.

Contrary to the weak association between maternal age of onset ( $<50$ years) and early onset of type $2 \mathrm{DM}$ ( $<40$ years) paternal onset of the disease before the age of 50 years did show a significant association with onset of the disease before the age of 40 . Whether this association has a genetic significance will need to be studied further.

This being a cross sectional study, the associations illustrated here lack temporality. A longitudinal study could possibly explore the various associations seen between the parental and sibling history of type $2 \mathrm{DM}$ with more power.

\section{Conclusion}

Maternal inheritance of DM was marginally more common among these subjects, which was not significant but there appears to be a greater inheritance among siblings with affected mothers. Further, there appears to be a significant association between early paternal age of onset and early onset of type $2 \mathrm{DM}$ in the offspring. These apparent associations need to be further explored. A longitudinal study could throw more light in this direction.

\section{Conflicts of interest}

All authors have none to declare.

\section{R E F E R E N C E S}

1. International Diabetes Federation. IDF Diabetes Atlas. 6th ed. Brussels, Belgium: International Diabetes Federation; 2013. http://www.idf.org/diabetesatlas.

2. American Diabetes Association. Diagnosis and classification of diabetes mellitus. Diabetes Care. 2013;36:S67-S74.

3. Karter AJ, Rowell SE, Ackerson LM, et al. Excess maternal transmission of type 2 diabetes. The Northern California Kaiser Permanente Diabetes Registry. Diabetes Care. 1999;22:938-943.

4. Klein BE, Klein R, Moss SE, Cruickshanks KJ. Parental history of diabetes in a population-based study. Diabetes Care. 1996;19:827-830.

5. Meigs JB, Cupples LA, Wilson PW. Parental transmission of type 2 diabetes: the Framingham Offspring Study. Diabetes. 2000;49:2201-2207.

6. Alcolado JC, Thomas AW. Maternally inherited diabetes mellitus: the role of mitochondrial DNA defects. Diabet Med. 1995;12:102-108. 
7. Pettitt DJ, Aleck KA, Baird HR, Carraher MJ, Bennett PH, Knowler WC. Congenital susceptibility to NIDDM. Role of intrauterine environment. Diabetes. 1988;37:622-628.

8. Mayer EJ, Newman B, Austin MA, et al. Genetic and environmental influences on insulin levels and the insulin resistance syndrome: an analysis of women twins. Am J Epidemiol. 1996;143:323-332.

9. Thorand B, Liese AD, Metzger MH, Reitmeir P, Schneider A, Löwel H. Can inaccuracy of reported parental history of diabetes explain the maternal transmission hypothesis for diabetes? Int J Epidemiol. 2001;30:1084-1089.

10. Report of a WHO Consultation. Obesity: Preventing and Managing the Global Epidemic894. World Health Organ Tech Rep Ser; 2000:1-253.

11. Atkinson MA, Eisenbarth GS. Type 1 diabetes: new perspectives on disease pathogenesis and treatment. Lancet. 2001;358:221-229.
12. Patel M, Patel IM, Patel YM, Rathi SK. A hospital-based observational study of type 2 diabetic subjects from Gujarat, India. J Health Popul Nutr. 2011;29:265-272.

13. Gale EA, Gillespie KM. Diabetes and gender. Diabetologia. 2001;44:3-15.

14. Mohan V, Sandeep S, Deepa R, Shah B, Varghese C. Epidemiology of type 2 diabetes: Indian scenario. Indian J Med Res. 2007;125:217-230.

15. Logue J, Walker JJ, Colhoun HM, et al. Do men develop type 2 diabetes at lower body mass indices than women? Diabetologia. 2011;54:3003-3006.

16. McCarthy M, Cassell P, Tran T, et al. Evaluation of the importance of maternal history of diabetes and of mitochondrial variation in the development of NIDDM. Diabet Med. 1996;13:420-428. 